superficial, escaso en su información e incapaz de plantear alguna idea digna de destacarse. $Y$ la misma sensación de desencanto produce el leer las páginas dedicadas a el manierismo en relación con la pintura de naturalezas muertas. Más cuerpo e interés, en cambio, tiene su opinión, contraria a la de Charles Sterling (La nature morte: de l'Antiquité d nos jours) en el sentido de que la pintura de bodegones se deriva directamente de los pintores cuatrocentistas y no procede, por la puerta falsa, de los marqueteros renacentistas.

En todo caso la obra que comentamos resulta interesante, a más de las razones dichas arriba, siempre que se tome como una serie de reflexiones inteligentes, más o menos ordenadas, más o menos sustentadas, acerca del género de bodegones, $\mathrm{y}$ no se imagine ver en ella un cstudio sólido sobre la materia: que ésa no parece haber sido su intención.

\title{
J. A. M.
}

Juan Somolinos Palencia: El surrealismo en la pintura mexicana, Mćxico, Arte Ediciones, 1973.

Bajo la idea rectora de que el surrealismo mexicano no se expresó de manera ortodoxa, Juan Somolinos construye su ensayo, siguiendo un esquema bien estudiado donde la ordenación lógica que rige la estructura en que sitúa a los artistas, se ve malograda y complicada por las denominacioncs sumamentc artificiosas con las que designa a estas agrupaciones.

Se ha escrito demasiado sobre el surrealismo como para poder considerar que este libro aporte nuevos conceptos o directrices más acertadas para el tema que trata. Sin embargo, la edición queda justificada como obra de divulgación al alcance económico de un público lector numeroso. Juan Somo. linos parece coincidir con las ideas que fundamentan el libro de la doctora Ida Rodrígucz Prampolini, El surrealismo y el arte fantástico de México, UNAM, Instituto de Investigaciones Estéticas, 1969. Difierc de esta autora en los términos que designan las diversas ramas del arte fantástico y también en cuanto a la importancia que da en la primera sección del libro, no sólo a los descubrimientos freudianos, sino a los de los precursores del método psicoanalítico; o sea al hipnotismo y al estudio de la histeria que hicieron célebre al doctor Charcot en el Hospital de la Salpetric̀re en París, e incluso cita a Pierre Janet, famoso médico y psiquiatra francés que muy poco o nada tuvo que ver con el surrealismo. Estas dos inclusiones parecen querer aportar algo a la comprensión de este movimiento, pero en realidad son notas, que aunque ofrecen interés desde otros ángulos, son accesorias al tema que se pretende tratar, aun y cuando los surrealistas europeos hayan celebrado fcstivamente las conocidas fotografías sobre curaciones de casos de histeria tomadas en el hospital de la Salpetrière.

Existe también el intento de explicar el porqué el surrealismo no logró anexarse al campo científico, sobre lo cual Somolinos expresa que la discusión entablada entre Sartre (quien acusó al surrealismo de destruir la objetividad) 
y los surrealistas para llegar a un acuerdo, fracasó "porque el surrealismo se frustró al pretender sobrepasar al antinomio de subjctivo ! objetion, al ptuto de negar lo objetivo e incorporarse artificialmente a la subjetividad", cxpresión demasiado elaborada y muy discutible, puesto que el surrcalismo, movimiento subjetivo en cuanto que se basa en la cxaltación de la propia subjetividad, no pretendió propiamente negar lo objetivo, sino que simplemonte funcionó dentro de otros márgenes y bajo otros parámctros.

Brevemente describe cl autor los antecedentes del movimicnto, sin detenerse con profundidad a examinar el dadaísmo (aspecto que constituve uno de los principales aciertos del libro de Ida Rodríguez, por lo bien fundamentado que presenta este análisis). Sufre Somolinos algunas confusiones cn cuanto a fechas $y$ épocas, por ejemplo: afirma que Apollinaire dio su réquiem al cubisno, consagrando al surrealimo como tendencia y dándole nombre al mismo tiempo. En realidad el término "surrealismo" es usido por Apollinaire en sustitución a "surnaturalismo", cxplicando que aquél no cxiste aún en los diccionarios, en una carta dirigida a Pul Dcrmóc en marzo de 1917, según cita Maurice Nadeau en su Historia del surrealismo. La fecha 1910, anotada como la del réquiem al cubismo, resulta particularmente equirocada si se tiene en cuenta que precisamente inicia la fase propulsión del movimicnto, con las primeras dos cxposiciones cubistas; por otra parte, el libro de Apollinaire titulado: Les peintres cubistes, fuc publicado en París lacia fines de 1913. Es de sobra conocido como para insistir más en cllo que antes de 1916, con la apertura del Cabaret Voltaire en Zurich, no existió corriente ni agrupación dadaísta, mucho menos surrealista, sino sólo tendencias generalizadas a lo largo de la historia en muchos casos aislados de artistas, que las practicaron y que después vinicron a ser considerados como precursores del surrealismo.

Después de explicar el nacimiento del movimicnto en Furopa, Somolinos introduce su trasposición a América a través del viaje de Breton a los listados Unidos en 1938, y posteriormente a México "coincidiendo con cl activo y" bien encaminado gobierno de Lázaro Cárdenas y con el asilo político de Trotsky". Hace cl autor aquí una obserración importante: la fantasía mexicana está por encima de la influencia bretoniana, obedece a su propia filosofía y se corresponde también con su actitud propia ante la vida: por eso en nuestro pais, desde la antigïedad hasta nuestros dias, cxisten obras que expresan ideas o sentimicntos donde el pensamiento mígico ancestral del mexicano aflora. De tal manera on México el objeto "surreal" aparece en forma natural, no es necesario realizar una búsqueda forzada para su hallazgo, ya que la creación mágica "está en las manos y cn la mente de todo nuestro pueblo". Siendo que csta idca constituye uno de los conceptos claves que esgrime Ida Rodríguez al tratar este asinto, Somolinos la cita, incluso transcribiendo un párrafo. Después de hacer un análisis breve de la exposición surrealista realizada en México en 1940, Somolinos pasa a dividir la influencia surrealista en muestro país en tres ctapas: pintura fantástica presurrcalista del siglo pasado; momento de ingreso del surrcalismo en México, donde aparcen los pintores mexicanos $y$ extranjeros quc actuaron bajo estc 
movimiento, y por último la pintura del último decenio "donde objetiva mente vemos el fracaso del pensamiento ortodoxo surrealista y cl gran incremento de la pintura fantástical $y$ decorativa". Sobre esta división básical realiza un cuadro sinóptico pormenorizado que aparece al final del libro antecediendo a la bibliografía, cuadro que indica el desarrollo del texto a partir de la división mencionada.

Desde luego cita a Posada y a Ruelas diciendo que "los dos pintores significaron expresiones opuestas que representaron claramente el sentir fantástico mexicano", lo cual es muy cierto, sólo que Posada no fue precisamente pintor y cn cuanto a Ruelas, sil información resulta deficientc, pucs afirma que fue dibujante, grabador con depuradas técnicas en aguafuerte "y más tarde realizado pintor"; en realidad ocurrió a la inversa: Ruclas fue siempre dibujante y pintor, ilustrador muy destacado y aguafuertista sólo durante los úitimos tres anos de su corta vida.

F.n la división que denomina "pintura fantástica mexicana activa durante la llegada de Breton" incluye a artistas muy disímbolos, cita entre otros a Adolfo Best, Julio Castellanos, Carlos Mérida, Roberto Montenegro, Juan O'Gorman, Rufino Tamayo, Dicgo Rivera, José Clementc Orozco, etcétera; ciertamente todos estos pintores realizaban una obra importante cuando Breton vino a México, pero sólo algunos pueden ser situados en la corricnte propiamente fantástica, y si bien es cierto que cn toda obra de arte es fácil que aparezca el clemento fantástico, como producto de la imaginación, Somolinos debió haber hecho una selccción más cuidadosa incluvendo sólo a aquellos quc, como Montenegro y O'Gorman, presentan una fucrte tendencia a expresarse por medio de la fantasía.

La siguicnte división incluye a "pintores surrcalistas mexicanos considerados así por Breton", hace destacar aquí a Frida Khalo y a Guillermo Meza. Tal vez el juicio sobre Frida sea una de las mejores partes del libro y no sólo eso, sino uno de los comentarios más acertados que se han escrito sobre esta pintora.

Su fuerte desco maternal, su sensualidad y sus profundas pasioncs debieron alternar con el dolor, la crucldad, la tristeza $y$ una negativa religiosidad; sus cuadros son reflejo de todos cstos sentimientos, sus pinceles impregnaron de esperanza los lienzos donde refugió su propia desesperación. Frida Khalo considerada como la primera surrealista mexicana no es la vida, el carácter ni la voluntad al scrvicio de este movimiento sino la imagen clara de un ser luumano encerrado en su atormentada existencia que expresó sus experiencias con un refinado sentido popular donde reveló claramente su propia realidad.

La división "pintores surrealistas cxtranjeros" se inicia dedicando un recuerdo a Antonin Artaud y a continuación enumerando al grupo de pintores que se asilaron en nuestro país por los efectos de la guerra civil española y de la Segunda Guerra Mundial: Leonora Carrington, Remedios Varo, los Horna, Wolfang Paalen, Alice Rahon. Algunas de las opiniones de Somolinos sobre Remedios Varo, a quien conoció y apreció mucho, considcríndose a sí mismo 
como heredero suyo (Somolinos es también pintor), son muy acertados por la objetividad $y$ honestidad con que están expuestos, sobrc todo si sc considera que para mucha gente Remedios Varo pasó a ser una especic de mito, suma de todas las virtudes artísticas. "La obra de Remedios Varo es popular, encaja en el gusto de la gran masia. . Su arte serviria de dorada puerta para algún día comprencler el surrealismo... Sus temas son el $A B C$ de la pintura fantástica, no así su depurada técnica que ha originado multitud de burdos imitadores."

Discutible y problemática es la sección que dedica a "pintores surrcalistas abstractos mexicanos y extranjeros", aceptando que exista un tipo de expresión surrealista en sentido abstracto, ésta se manifiesta en el alutomatismo psíquico que en buena medida caracteriza la obra de algunos artistas del cxpresionismo abstracto o del tachismo, pero es difícil considerar que los ejemplos que cita Somolinos (Gunther Gerzso v Matías Gocritz) correspondin en alguna forma a la tenclencia surrealista.

Las últimas divisiones son dedicadas a examinar dirersos aspectos de la "pintura subjetiva fantástica y decorativa" que florce desde 1938 y que se ha incrementado sobre todo de diez anos a li fecha. $\Lambda$ amilizar estas corrientes Somolinos llega a la conclusión de que el surrealismo en México fracasó, pero que sin embargo estimuló las distintas expresiones artisticas cncaminando sus tendencias hacia una fantasía y uma imaginación propias de nuestro medio. Este hecho lo lleva a considerar que efectivamente existen grupos numcrosos de pintores atraídos por la idea surreal, pero que entre ellos hay muchos que se definen por este tipo de expresión por el resultado comcrcial y la demanda de un público curioso y snob. Las subdivisiones y los artistas en cllas incluidos, son demasiadas como para hacer una reseña detenida, baste considerar que difcrencia a los pintores "fantasticosubjetiros" (como Silvio Aguilera, Xavier Lisqueda y Pedro Fricdeberg) de aquellos que practican el collage y de los que se manifiestan en un estilo "fantásticodecorativo", que pretenden ser incluidos dentro del surrealismo "desconociendo absolutamente sus principios y desde luego su historia".

En esta última afirmación podría haber ahondado el autor, quien es lo suficientemente sagaz para comprender que la cursilería auténtica tienc su valor, micntras que aquélla de "dudoso gusto" es precisamente la que se manifiesta en los motivos decorativos de estos numerosos pintores que pretenden presentar sus obras bajo el rubro de surrealistas. Fl análisis que este grupo de pintores necesitil, no por sus valores, sino precisamente por la carencia de ellos, no es enfrentada por Somolinos con la profundidad que cl caso amerit:al, si bien es cierto que es perfectamente consciente de cste fenómeno.

El libro vienc complementado por amplísima bibliografía en varios idiomas. Surge la duda sobre el conocimiento meditado por parte del autor de todos los libros que reseña, ya que tal rez otro hubiera sido ol resultado de su ensayo sobre el surrealismo, si a su espíritu perceptivo y afinada sensibilidad, hubiera aunado un sólido bagaje de conocimientos sobre tan importinte temal. 